\title{
Publisher Correction: A DHODH inhibitor increases p53 synthesis and enhances tumor cell killing by p53 degradation blockage
}

\author{
Marcus J.G.W. Ladds, Ingeborg M.M. van Leeuwen, Catherine J. Drummond et al. ${ }^{\#}$
}

Correction to: Nature Communications https://doi.org/10.1038/s41467-018-03441-3, published online 16 March 2018

The original PDF version of this Article listed the authors as "Marcus J.G.W. Ladds," where it should have read "Marcus J. G. W. Ladds, Ingeborg M. M. van Leeuwen, Catherine J. Drummond et al."”.

Also in the PDF version, it was incorrectly stated that "Correspondence and requests for materials should be addressed to S. Lín.", instead of the correct "Correspondence and requests for materials should be addressed to S. Laín."

This has been corrected in the PDF version of the Article. The HTML version was correct from the time of publication.

Published online: 22 May 2018

(c) Open Access This article is licensed under a Creative Commons Attribution 4.0 International License, which permits use, sharing, adaptation, distribution and reproduction in any medium or format, as long as you give appropriate credit to the original author(s) and the source, provide a link to the Creative Commons license, and indicate if changes were made. The images or other third party material in this article are included in the article's Creative Commons license, unless indicated otherwise in a credit line to the material. If material is not included in the article's Creative Commons license and your intended use is not permitted by statutory regulation or exceeds the permitted use, you will need to obtain permission directly from the copyright holder. To view a copy of this license, visit http://creativecommons.org/licenses/by/4.0/.

(C) The Author(s) 2018 
Marcus J.G.W. Ladds ${ }^{1,2}$, Ingeborg M.M. van Leeuwen', Catherine J. Drummond', Su Chu ${ }^{3}$, Alan R. Healy ${ }^{4}$, Gergana Popova1, Andrés Pastor Fernández ${ }^{1}$, Tanzina Mollick ${ }^{1,2}$, Suhas Darekar ${ }^{1,2}$, Saikiran K. Sedimbi ${ }^{1,2}$, Marta Nekulova ${ }^{1,5}$, Marijke C.C. Sachweh ${ }^{1}$, Johanna Campbell ${ }^{6}$, Maureen Higgins ${ }^{6}$, Chloe Tuck ${ }^{1}$, Mihaela Popa ${ }^{7}$, Mireia Mayoral Safont ${ }^{7}$, Pascal Gelebart ${ }^{7}$, Zinayida Fandalyuk ${ }^{7}$, Alastair M. Thompson $^{8}$, Richard Svensson ${ }^{9}$, Anna-Lena Gustavsson ${ }^{10}$, Lars Johansson ${ }^{10}$, Katarina Färnegårdh ${ }^{11}$, Ulrika Yngve ${ }^{12}$, Aljona Saleh ${ }^{12}$, Martin Haraldsson ${ }^{11}$, Agathe C.A. D'Hollander ${ }^{4}$, Marcela Franco ${ }^{1}$, Yan Zhao ${ }^{13}$, Maria Håkansson ${ }^{14}$, Björn Walse ${ }^{14}$, Karin Larsson (1) ${ }^{1}$, Emma M. Peat ${ }^{15}$, Vicent Pelechano ${ }^{2}$, John Lunec ${ }^{13}$, Borivoj Vojtesek ${ }^{5}$, Mar Carmena (i) ${ }^{15}$, William C. Earnshaw ${ }^{15}$, Anna R. McCarthy ${ }^{1}$ Nicholas J. Westwood (10 ${ }^{4}$, Marie Arsenian-Henriksson', David P. Lane ${ }^{1,2}$, Ravi Bhatia ${ }^{3}$, Emmet McCormack ${ }^{7,16} \&$ Sonia Laín ${ }^{1,2}$

\footnotetext{
'Department of Microbiology, Tumor and Cell Biology (MTC), Karolinska Institutet, SE-171 77 Stockholm, Sweden. ${ }^{2}$ SciLifeLab, Department of Microbiology, Tumor and Cell Biology (MTC), Karolinska Institutet, Tomtebodavägen 23, SE-171 21 Stockholm, Sweden. ${ }^{3}$ Division of Hematology and Oncology, Comprehensive Cancer Center, 1720 2nd Avenue South, NP2540, Birmingham, AL 35294-3300, USA. ${ }^{4}$ School of Chemistry and Biomedical Sciences Research Complex, University of St. Andrews and EaStCHEM, St. Andrews, Fife, Scotland KY16 9ST, UK. ${ }^{5}$ RECAMO, Masaryk Memorial Cancer Institute, Zluty Kopec 7, 65653 Brno, Czech Republic. ${ }^{6}$ Centre for Oncology and Molecular Medicine, University of Dundee, Ninewells Hospital and Medical School, Dundee, Tayside DD1 9SY, UK. ${ }^{7}$ Centre for Cancer Biomarkers, CCBIO, Department of Clinical Science, Hematology Section, University of Bergen, 5021 Bergen, Norway. ${ }^{8}$ Department of Breast Surgical Oncology, MD Anderson Cancer Center, Holcombe Boulevard, Houston 77030, USA. ${ }^{9}$ Department of Pharmacy, Uppsala University Drug Optimization and Pharmaceutical Profiling Platform (UDOPP), Department of Pharmacy, Uppsala University, SE-752 37 Uppsala, Sweden. ${ }^{10}$ Chemical Biology Consortium Sweden, Science for Life Laboratory, Division of Translational Medicine and Chemical Biology, Department of Medical Biochemistry and Biophysics, Karolinska Institutet, SE-171 21 Stockholm, Sweden. ${ }^{11}$ Drug Discovery and Development Platform, Science for Life Laboratory, Tomtebodavägen 23, SE-171 21 Solna, Sweden. ${ }^{12}$ Department of Medicinal Chemistry, Science for Life Laboratories, Uppsala University, SE-751 23 Uppsala, Sweden. ${ }^{13}$ Newcastle Cancer Centre, Northern Institute for Cancer Research, Newcastle University, Newcastle NE1 7RU, UK. ${ }^{14}$ SARomics Biostructures, Medicon Village, SE-223 81 Lund, Sweden. ${ }^{15}$ The Wellcome Trust Centre for Cell Biology, Institute of Cell Biology, University of Edinburgh, Edinburgh EH9 3JR, UK.

${ }^{16}$ Department of Medicine, Haematology Section, Haukeland University Hospital, Bergen, Norway. These authors contributed equally: Marcus J. G. W. Ladds, Ingeborg M. M. van Leeuwen, Catherine J. Drummond. Deceased: Anna R. McCarthy.
} 